\title{
ANSS-Advanced National Seismic System
} Advancing National Seismic Safety-Accomplishments FY2002

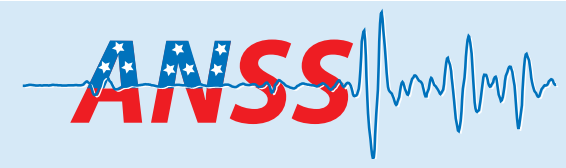

$\mathrm{T}$

he Advanced National

Seismic System (ANSS) provides accurate and timely information about seismic events and their effects on buildings and structures using modern monitoring methods and technologies. Continuing the original objective conceived in the 1980's of a National Seismic System, ANSS strives to unify seismic monitoring in the United States. It provides a framework to modernize instrumentation and revolutionize data availability for research, engineering, and public safety.

\section{University of Utah Prepared for Olympics Earthquakes}

University of Utah seismologists were on duty around the clock during the 2002 Winter Olympics, armed with a new $\$ 1.2$ million system designed to quickly supply public safety information if any disruptive earthquakes were to shake the Winter Games. The improved earthquake-monitoring system of sensors, computers, and telecommunications equipment was made possible with $\$ 965,000$ in funds and equipment provided by the U.S. Geological Survey (USGS), and another $\$ 235,000$ in funds and personnel support from the State of Utah. Although installation was accelerated to be in place for the 2002 Olympic Winter

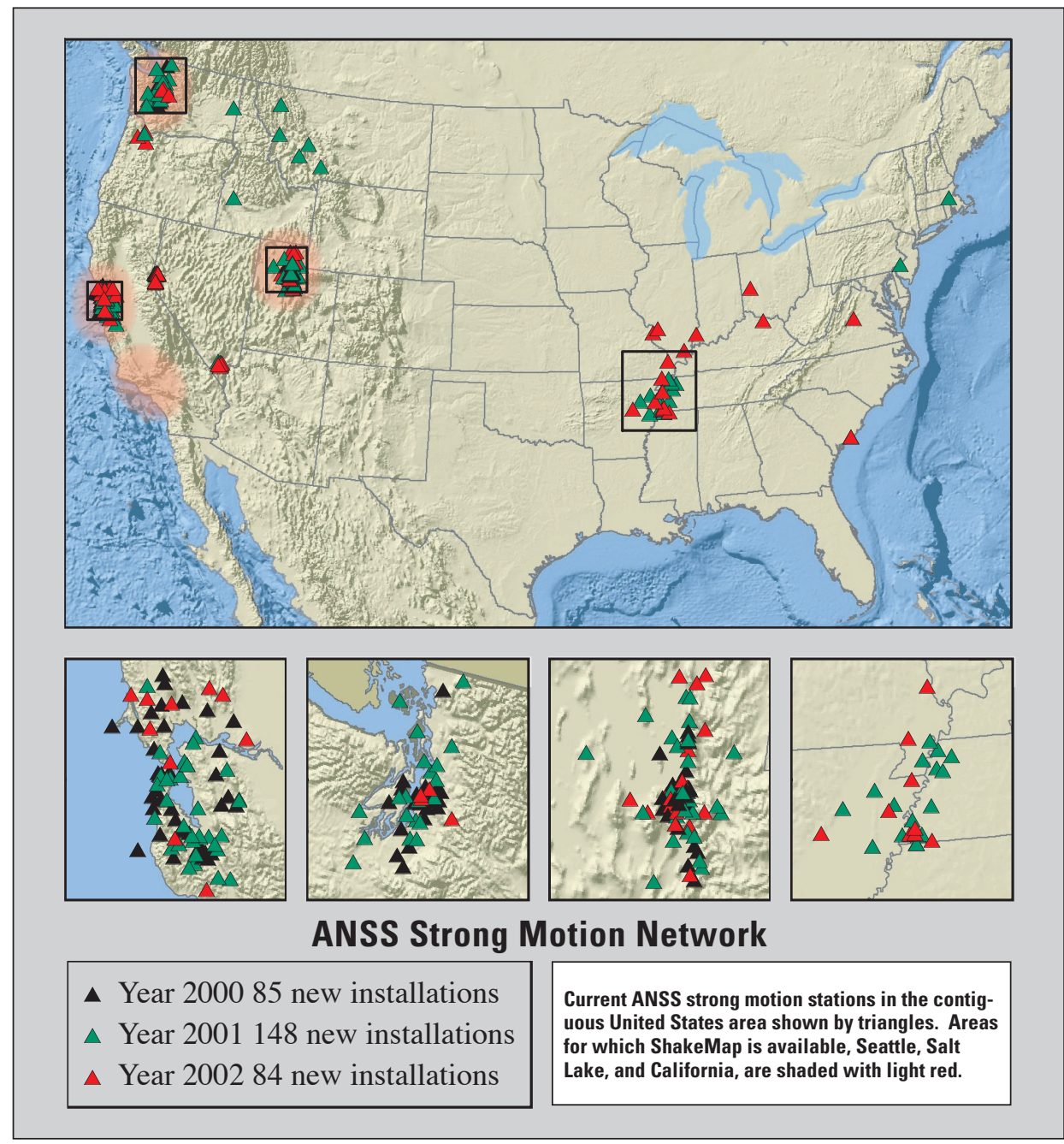

Games, the primary motivation is to provide for the long-term earthquake safety needs in Utah's dramatically growing Wasatch Front area.

\section{ANSS Comes to Memphis}

The ANSS in the Central United

States was inaugurated with a ribboncutting ceremony on October 29, 2002, at the USGS office in Memphis, Tenn., in collaboration with the Center for Earthquake Research and Information. Thirty-two new ANSS instruments in the mid-America region form part of a nationwide network of sophisticated instruments that monitor earthquakes throughout the United States and provide near-real-time information on earthquake shaking.

\section{Real-Time Earthquake Products} Featured on Redesigned Website The USGS Earthquake Program personnel unveiled a number of new real-time earthquake tools and a redesigned website to enhance information delivery during the times when people want it most - immediately after a damaging event. New earthquake activity maps, community 
intensity reports, and automated web pages linking together historical seismicity, event summaries, ShakeMaps, fault displacement, and other technical information are now available within minutes of a significant event at http://earthquake.usgs.gov/.

\section{Shaking It Up in Alaska}

A ShakeMap portraying the variations in shaking intensity from the November 3, 2002, magnitude 7.9 earthquake was produced by USGS scientists within 5 days of the temblor. The map is the first ShakeMap produced for the State of Alaska and is considered a prototype. The map focuses on the central and southcentral portions of the State, the area most affected by the quake. Most notable on the map is a $295-\mathrm{km}$-long and several-kilometer-wide zone of extremely violent shaking centered around the Denali and branching Totschunda faults. Not surprisingly, the shaking corresponds to the area where heavy highway, pipeline, and structural damage was concentrated.

\section{Response to Noteworthy Earthquakes Across the United States}

USGS scientists and ANSS university collaborators kept busy in 2002 responding to a number of noteworthy earthquakes across the country. On April 20, 2002, a magnitude 5.1 earthquake hit near Au Sable Forks in the Adirondack Mountains region of New York. That earthquake was felt throughout New England, and as far away as Cleveland, Ohio, Baltimore, Md., and Quebec, Canada, a region well over $950 \mathrm{~km}$ across. Bridges and roads were damaged, and some foundations were reported cracked. More than 9,500 people provided personal accounts of the event through an interactive web-based tool known as "Did-You-Feel-It?". After combining the account with the contributor's ZIP Code number, USGS scientists were able to integrate the information into

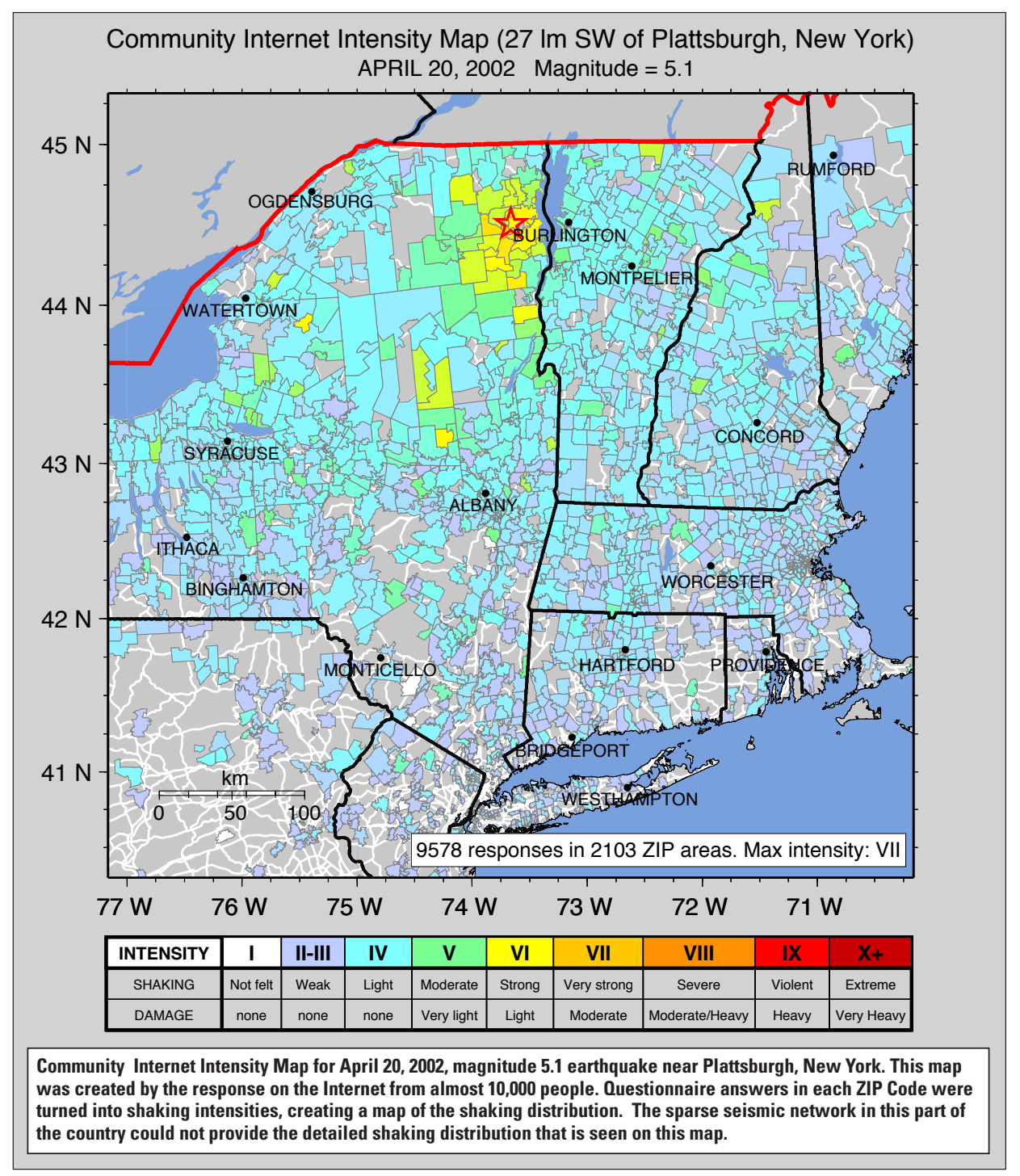

a community-based shaking intensity map of the region - one of the first for New England. On May 13, 2002, a magnitude 4.9 earthquake occurred south of Silicon Valley, Calif., near the town of Gilroy. Although producing no damage, the earthquake was felt strongly across the Bay Area (a $400 \mathrm{~km}$ diameter), and resulted in approximately 17,000 contributions to the web-based "Did-You-Feel-It?" questionnaire as well as a surge in web traffic (peaking at 3,000 hits per second). Last was the magnitude 5.0 Darmstad earthquake in southern Indiana. This event produced little damage but was felt broadly across the States of Indiana, Illinois, Kentucky, and Tennessee. The large community interest in each of the moderate earthquakes demonstrates the importance of satisfying the Nation's desire for in-depth, timely earthquake information once the ground begins to shake. ANSS products are increasingly meeting this need.

\section{For More Information}

Contact:

USGS Geologic Hazards Team

Federal Center PO Box 25046 MS966

Denver, CO 80225

303-273-8582

ANSS Website:

http://www.anss.org/

ShakeMap:

http://earthquake.usgs.gov/shakemap/

Did You Feel It?

http://earthquake.usgs.gov/shake/

Earthquake Hazards Program

http://earthquake.usgs.gov/

Written by Jill McCarthy

Graphic Design by Lisa Wald 